\title{
Avaliação de impacto no Brasil: é possível mensurar impactos de programas de formação docente?
}

ADRIANA BAUER*

\section{RESUMO}

O presente artigo visa a compartilhar as vicissitudes de uma proposta de avaliação de impacto de um programa educacional, objeto atual de análise da autora. Tal estudo, provisoriamente intitulado "Avaliação de possíveis impactos de programas de formação docente: a experiência do Programa Letra e Vida", originou-se da preocupação com a escassez de trabalhos que buscassem mensurar impactos de programas educacionais no Brasil. O texto discute o conceito de "avaliação de impacto" e analisa as dificuldades metodológicas inerentes a esse tipo de avaliação. Traz exemplos dos desafios subjacentes à mensuraçáo de impacto em educação que frustraram o projeto inicial de doutoramento da autora e as tentativas realizadas no sentido de superar tais obstáculos. A motivação para a produção do artigo não é, portanto, compartilhar resultados de pesquisa, mas sim propor a discussão das dificuldades encontradas e dos caminhos metodológicos que podem ser utilizados para o estudo de efeitos de programas, visando ao aprofundamento das reflexóes sobre a temática.

Palavras-chave: Avaliação do programa, Formação de professores, Saresp, Programa Letra e Vida.

* Doutoranda em Educação, Programa de Pós-Graduação da Faculdade de Educação da Universidade de São Paulo e Pesquisadora da Fundação Carlos Chagas (dri_bauer@yahoo.com.br). 


\section{RESUMEN}

El presente artículo tiene como objetivo compartir las vicisitudes de una propuesta de evaluación de los impactos de un programa educacional. Este es el objeto actual de análisis de la autora. Tal estudio, con el título provisorio de "Evaluación de los posibles impactos de programas de formación docente: la experiencia del Programa Letra e Vida", surgió de la preocupación por la escasez de trabajos que midiesen los impactos de programas educacionales en Brasil. El texto discute el concepto de "evaluación de impacto" y analiza las dificultades metodológicas inherentes a este tipo de evaluación. Aporta ejemplos de los desafíos subyacentes a la medición del impacto en educación, que frustraron el proyecto inicial de doctorado de la autora, y los intentos realizados con el fin de superar tales obstáculos. La motivación para producir el artículo no es, por lo tanto, compartir los resultados de una investigación, sino proponer la discusión de las dificultades encontradas y de los caminos metodológicos que se pueden utilizar para el estudio de efectos de programas, con el objetivo de profundizar las reflexiones sobre este tema.

Palabras clave: Evaluación del programa, Formación de profesores, Saresp, Programa Letra e Vida.

\section{ABSTRACT}

This article aims at sharing the hardships of an evaluation proposal of the impact of an educational program, the present object of the author's analysis. This study, provisionally named "Evaluation of possible impacts of teacher education programs: the experience of the Letra e Vida Program", arose from a concern with the lack of studies that attempted to measure impacts of educational programs in Brazil. The text discusses the concept of "impact evaluation" and analyzes the methodological difficulties inherent to this type of evaluation. It also provides examples of challenges underlying the measurement of impact in education which frustrated the author's initial doctoral project, and the attempts made to try to overcome such obstacles. The motivation for this article, then, is not to share research results, but to propose the discussion of the difficulties encountered and of the methodological approaches that can be used to study the effects of the programs, so as to widen the reflections on this topic.

Keywords: Program evaluation, Teacher education, Saresp, Letra e Vida Program. 


\section{INTRODUÇÃO}

Algumas políticas educacionais implementadas no Brasil, desde meados da década de 1990, destinaram parte dos recursos disponíveis à formaçáo e ao desenvolvimento dos professores, visando, entre outros objetivos, à melhoria da qualidade do ensino.

Como exemplo, pode-se citar o Fundo de Manutenção e Desenvolvimento do Ensino Fundamental e de Valorização do Magistério (Fundef) e o Fundo de Manutenção e Desenvolvimento da Educação Básica e de Valorização dos Profissionais da Educaçáo (Fundeb). Primeira iniciativa de política de fundos, estabelecida após o período da redemocratização no Brasil, o Fundef subvinculou $60 \%$ dos recursos destinados ao ensino fundamental à formaçáo e ao desenvolvimento dos professores, enquanto o Fundeb manteve a mesma subvinculaçăo de recursos para a formação, ampliando-a a todos os professores de educação básica.

Quer seja para o ensino fundamental, quer contemple toda a educação básica, ambas as iniciativas expandiram consideravelmente a possibilidade dos sistemas educacionais designarem recursos para o desenvolvimento profissional dos professores. Além disso, diversas secretarias estaduais de educação vêm sistematicamente investindo na formação dos professores, visando a mudanças na qualidade do ensino ofertado.

No caso específico do Estado de Sáo Paulo, diferentes açôes de formaçáo contínua vêm sendo planejadas e ofertadas, sendo a formaçáo docente apresentada como um dos eixos da segunda gestão do governo Alckmin (2003-2006), inserida em um projeto político mais amplo, focado na "inclusão social e melhoria do ensino" (São Paulo, 2003, p. 13). ${ }^{1}$

Nesse sentido, a qualificaçáo docente e a melhor atuaçáo do professor têm sido considerados fatores preponderantes para o desenvolvimento da qualidade de ensino e do desempenho dos estudantes, por meio do "aprimoramento das práticas escolares" (Sẫo Paulo, 2003, p. 15).

Inclusive ao referenciar os sistemas de avaliação como importantes formas de acompanhamento desse "aprimoramento", o documento que lançou as diretrizes para a política educacional do governo Alckmin fez alguns anúncios sobre a necessidade de avaliaçáo das açóes implementadas. Náo foram especificados,

\footnotetext{
${ }^{1}$ A existência de programas de educaçáo continuada foi mantida no governo José Serra (2007-2010) embora aparentemente com menor ênfase. $O$ apoio a essas atividades faz parte das dez metas para a educação, lançadas pela Secretária de Educação Maria Helena Guimaráes de Castro, a serem atingidas até 2010.
} 
no entanto, critérios que pudessem balizar essa avaliação e o monitoramento dos programas implementados.

Apesar de as intenções de acompanhamento e avaliação dos programas estarem divulgadas nos documentos oficiais da Secretaria da Educação do Estado de São Paulo daquela gestão, não foram encontradas referências a essa avaliação em outros documentos pesquisados. Mesmo nos documentos específicos do programa de formação continuada Teia do Saber, que deu origem aos programas de formação da Secretaria da Educação (entre os quais o "Letra e Vida"), não foram encontradas informaçóes que permitissem vislumbrar como se daria sua avaliaçáo.

O fato de tal avaliaçáo náo estar especificada nos documentos chamou a atenção da pesquisadora, dada a ênfase que vem sendo colocada pelas políticas de diversas áreas na avaliação dos resultados dos programas como fator essencial para seu redimensionamento.

Para além da análise documental, durante a pesquisa empírica, realizada pela autora no processo de elaboração da sua dissertação (Bauer, 2006), foi possível verificar que sáo raros os momentos em que programas da Secretaria da Educação do Estado de São Paulo são avaliados formalmente. Além disso, as avaliaçóes, quando realizadas, tendem a focar a implementação do programa ou seus resultados imediatos, deixando de lado o estudo sobre o impacto dos mesmos, entendido aqui como efeitos que se mantêm a longo prazo.

Não seria de esperar que no momento em que o discurso da qualidade, da eficiência e eficácia de programas fosse utilizado como justificativa das açóes desencadeadas e a avaliaçáo dos impactos dessas açóes fosse incorporada aos desenhos das políticas?

Tal questionamento deu origem a outros: seria possível saber em que medida os esforços realizados, no sentido de melhorar a qualidade da formaçáo docente, surtem efeito sobre a "qualidade do trabalho docente" ou sobre a atuação dos professores? Como avaliar a influência que programas de formação têm acerca da atuação docente e do desempenho dos alunos? Ou, de forma geral, quais seriam os possíveis impactos das ações formativas na prática docente e nos resultados dos alunos?

Observa-se que nos documentos do "Letra e Vida", assim como nos outros pesquisados, foram feitas afirmaçóes a respeito da necessidade de seu acompanhamento e avaliação, mas não são encontradas especificaçóes acerca de mecanismos de avaliação dos resultados e impactos do programa.

Foi a partir dessas questões e da lacuna de propostas de avaliaçóes oficiais do programa que o objeto e problema do estudo proposto pela autora, em nível de 
doutoramento, foram definidos: análise de eventuais impactos do Programa Letra e Vida, implantado em 2003 pela Secretaria da Educação do Estado de São Paulo. Para esse estudo a análise focaliza os professores da $1^{\text {a }}$ série do ciclo de alfabetizaçáo (ensino fundamental 1).

Este é um programa de formaçáo para professores alfabetizadores, destinado aos docentes do primeiro segmento do ensino fundamental, mais especificamente aos professores de $1^{\mathrm{a}}$ e $2^{\mathrm{a}}$ séries.

O objetivo geral da pesquisa é analisar eventuais impactos do Programa Letra e Vida na atuação dos professores e no desempenho dos alunos. Os objetivos específicos são:

- Identificar evidências, na organizaçáo do trabalho em sala de aula, da utilizaçáo de princípios metodológicos do "Letra e Vida".

- Analisar eventuais diferenças, no desempenho de alunos de escolas estaduais no Saresp, que possam ser atribuídas ao "Letra e Vida".

- Procurar indícios, nos discursos dos professores, que evidenciem a influência (ou não) da formação recebida em sua prática cotidiana.

- Elencar dificuldades e desafios que se impóem aos professores para fazer uso dos conhecimentos teóricos adquiridos durante o curso em sua prática cotidiana.

Feitos os primeiros delineamentos, a autora passou à análise documental e ao levantamento de dados para realizaçáo da pesquisa. Foi quando as primeiras dificuldades e desafios se impuseram, levando-a a refletir sobre a metodologia inerente a esse tipo de avaliação e, ainda mais, sobre o significado conceitual de avaliação de impacto, como será visto a seguir.

\section{O QUE É AVALIAÇÃO DE IMPACTO?}

A avaliaçáo de um programa social pode envolver diversas etapas: análise da proposta (examina se o programa é importante e relevante para o objetivo pré-definido e se o desenho está adequado, projeta possíveis resultados, etc.), da implementaçáo (avalia se o projeto está sendo conduzido conforme o planejado), dos resultados (analisa se o programa implementado atingiu os objetivos previamente definidos) e dos impactos, entendidos aqui como resultados e efeitos da intervenção a longo termo e que se mantêm mesmo após o término da intervenção.

Contudo, na vasta literatura existente sobre avaliação de programas, nem sempre essas são as etapas mencionadas e, tampouco, os conceitos utilizados por diversos 
autores se equivalem sendo que, muitas vezes, a ideia de impacto está incorporada na avaliação de resultados, e os termos utilizados como sinônimos.

Mesmo dentre os autores que fazem distinçáo entre "resultados" e "impactos", observa-se que as definiçóes de avaliação de impacto são diversas, havendo pouco consenso, nas referências pesquisadas, sobre o significado do termo.

Michael Scriven, por exemplo, no clássico Evaluation Thesaurus, define ${ }^{2}$ avaliação de impacto como "uma avaliaçấo focada nos resultados ou retornos do investimento, em vez de no processo, na entrega, ou na avaliação da implementação"3 (1991, p. 190).

Nesse exemplo, nota-se que a definiçáo de impacto relaciona-se ao foco da avaliação, e pode-se inferir que impactos e resultados (outcomes) são indistintamente entendidos pelo autor como "efeitos", ou seja, possuem uma natureza relacional com a intervenção, podendo ocorrer "durante", "ao final" da intervenção ou "posteriormente" (Scriven, 1991, p. 250). O exemplo do autor ilustra a tendência do uso intercambiável entre esses termos, encontrados em parte da literatura destinada à avaliação de programas (Weiss, 1998; Stufflebeam; Webster, 1980), como será exemplificado a seguir.

Mohr (1992), por exemplo, utiliza "análise de impacto" e aponta que impactos ocorrem quando uma intervenção afeta o estado de um objeto ou fenômeno "mais de uma vez":

Vamos tomar o termo análise de impacto para significar a determinação da extensão em que um conjunto de atividades humanas dirigidas $(\mathrm{X})$ afeta $\mathrm{o}$ estado de alguns objetos ou fenômenos $\left(Y_{1}, \ldots, o Y_{k}\right)$ - pelo menos algumas vezes determinando por que razão os efeitos foram táo pequenos, ou grandes, como acabaram por ser. (p. 1$)^{4}$

${ }^{2}$ Como a maioria das citaçóes utilizadas neste artigo provém da literatura estrangeira, optou-se por colocar as citaçóes originais, a fim de preservar a fidedignidade do texto, que poderia ser prejudicada por traduçóes equivocadas. Contudo, para garantir o acesso à informaçáo a todos os leitores, uma traduçáo livre foi elaborada pela autora, sempre que recorreu a passagens para reforçar ou exemplificar os argumentos.

3 "An evaluation focused on outcomes or payoff rather than process, delivery, or implementation evaluation" (Scriven, 1991, p. 190).

4 "Let us take the term impact analysis to mean determining the extent to which one set of directed human activities $(X)$ affected the state of some objects or phenomena $\left(Y_{1}, \ldots, Y_{k}\right)$ - at least sometimes - determining why the effects were as small or large as they turned out to be." (Mohr, 1992, p. 1) 
Para esse autor, isso significa que para poder atribuir um efeito (o estado de algum objeto ou fenômeno) a uma determinada causa (atividade humana dirigida) é necessário que, independentemente do contexto, a relaçáo se mantenha. Ou seja, deve ser possível repetir o experimento ou a intervençáo algumas vezes, obtendo os mesmos tipos de resultados, para poder lhe atribuir a condição de impacto. Essa característica da relação de causalidade também é apontada por Baker (2000) em sua definição de avaliação de impacto. Contudo, a autora não toca na necessidade de replicabilidade:

A intenção da avaliação de impacto é determinar mais amplamente se o programa teve os efeitos desejados nos indivíduos, domicílios e instituiçóes e se aqueles efeitos podem ser atribuídos à interveção do programa. Avaliaçóes de impacto também podem explorar consequências não previstas, positivas ou negativas, nos beneficiários. (p. 1) $)^{5}$ [grifos meus]

Para Baker a avaliaçáo de impacto náo somente se preocupa em mensurar/ interpretar os resultados do programa, mas analisa em que medida eles podem ser atribuídos ao programa e somente a ele. Nesse sentido, a avaliaçáo de impacto é entendida, tal qual em Scriven, como a mensuração do efeito de determinada intervenção (um programa educacional, por exemplo) sobre determinado alvo, a fim de saber em que medida houve alteraçáo na situaçáo inicial. A diferença entre Baker e Scriven é que a primeira busca diferenciar a avaliação de impacto da avaliação de resultados.

Outro aspecto que gera diferenças na teoria que trata de avaliação de impacto refere-se ao momento em que ela é realizada, pois a terminologia também aparece relacionada ao uso prévio da avaliação, com o objetivo de prever impactos possíveis de um programa antes de sua implementação:

Ex-ante ou avaliação de impacto: uma avaliação que visa prever a probabilidade de alcançar os resultados esperados de um programa ou intervenção, ou a previsão de seus efeitos inesperados. Esta é realizada antes que o programa ou a intervençáo sejam formalmente aprovados ou iniciados. Exemplos comuns de avaliação ex-ante são avaliaçôes de impac-

\footnotetext{
5 "Impact evaluation is intended to determine more broadly whether the program had the desired effects on individuals, households, and institutions and whether those effects are attributable to the program intervention. Impact evaluations can also explore unintended consequences, whether positive or negative, on beneficiaries." (Baker, 2000, p. 1)
} 
to ambiental e/ou avaliaçóes de impacto social e estudos de viabilidade. (Independent..., 2006) ${ }^{6}$

$\mathrm{Na}$ citação, avaliação ex-ante e impact assessment são utilizadas como sinônimos, enquanto o uso mais comum do conceito de avaliação de impacto, relativa à medida dos efeitos de determinada iniciativa, usualmente a identifica como avaliação ex-post. Ressalta-se, aqui, o uso de assessment (normalmente relacionado à avaliação de habilidades ou cognição, ou seja, à avaliação de características de pessoas) e evaluation (mais comumente relacionado à avaliação de programas, produtos, fenômenos, etc.), indistintamente, também como sinônimos.

Impact assessment é outra expressão usada para designar a avaliação focada em resultados ligados diretamente a determinada intervenção. Bickman (2005), por exemplo, no verbete que produziu para a Encyclopedia of Evaluation prefere o uso do termo assessment:

Avaliação de impacto é uma avaliação focada nos resultados ou impactos de um programa, política, organização ou tecnologia. Avaliaçôes de impacto tipicamente tentam fazer inferência causal que conecta o avaliado com o resultado. [...] Avaliação de impacto também é referenciada como resultado, impacto ou avaliação somativa. (Bickman, 2005, p. 194)

A Organização para a Cooperação Econômica e o Desenvolvimento (OCDE) também reforça que "impacto" é o efeito causado, direta ou indiretamente, por uma intervenção, claramente atribuindo esse tipo de avaliação ao final do processo de implementação do programa:

O ponto de partida é a definiçáo de impacto do Comitê de Assistência ao Desenvolvimento (CAD), que é: efeitos de longo-prazo, positivos e negativos, primários ou secundários, produzidos por uma intervençáo para o desenvolvimento,

6 "Ex-ante evaluation or impact assessment: an assessment which seeks to predict the likelihood of achieving the intended results of a programme or intervention or to forecast its unintended effects. This is conducted before the programme or intervention is formally adopted or started. Common examples of ex-ante evaluation are environmental and/or social impact assessments and feasibility studies". (Independent..., 2006)

7 "Impact assessment is an evaluation focused on the outcomes or impact of a program, policy, organization, or technology. Impact assessments typically try to make a causal inference that connects the evaluand with an outcome. [...] Impact assessment is also referred to as outcome, impact, or summative evaluation". (Bickman, 2005, p. 194) 
direta ou indiretamente, intencional ou involuntariamente. Esta definiçáo amplia avaliaçâo de impacto para além de efeitos diretos para incluir a gama completa de impactos em todos os níveis da cadeia de resultados. (OECD, 2008) ${ }^{8}$

Observa-se nessa definição o uso do termo "impacto" relacionado ao momento em que se dá a avaliação, sendo comum na literatura o uso da palavra resultados (outcomes) associada a efeitos de curto e médio prazos, enquanto avaliaçáo de impacto é associada aos resultados de longo termo, e, portanto, vai além de avaliar apenas o que aconteceu após uma intervenção (Cohen; Franco, 2008).

Nessa altura, o leitor pode estar se questionando se há realmente diferenciaçáo entre avaliaçóes de impactos e avaliaçóes de resultados, ou se a questão é apenas semântica, pois a ambas é atribuído um efeito de uma determinada intervenção.

Parece inegável que há uma questáo política no uso terminológico e que o que está em jogo vai além da semântica, pois o termo "impacto" pode implicar, a depender do contexto, uma conotação muito mais forte do que apenas a utilizaçáo do termo "resultado" ou "resultado de longo prazo".

Contudo, o Banco Mundial traz uma definição que permite estabelecer uma diferenciação clara entre avaliações de resultados e de impactos:

Embora haja debate dentro da profissão sobre a definição precisa de avaliação de impacto, o uso do termo pela NONIE ${ }^{9}$ provém da adoção da definiçáo de impacto do Comitê de Assistência ao Desenvolvimento (CAD) da Organização para a Cooperaçáo Econômica e o Desenvolvimento (OCDE), como "efeitos de longo-termo positivos ou negativos, primários ou secundários, produzidos por uma intervenção em desenvolvimento, direta ou indiretamente, intencional ou não-intencional". Adotar a definiçẫo do CAD leva a um foco de duas premissas subjacentes às avaliaçóes de impacto: (a) atribuiçáo: as palavras "efeitos produzidos por" [...] implicam uma abordagem para avaliação de impacto que é atribuir impactos a intervençóes, em vez de apenas avaliar o que

8 "The starting point is the Development Assistance Committee (DAC) definition of "impact", which is: 'positive and negative, primary and secondary long-term effects produced by a development intervention, directly or indirectly, intended or unintended'. This definition broadens impact evaluation beyond direct effects to include the full range of impacts at all levels of the results chain". (OECD, 2008)

${ }^{9}$ NONIE (Network of Networks on Impact Evaluation) é uma rede composta pela Rede de Avaliação da OCDE, pelo Grupo de Avaliaçáo das Naçóes Unidas, pelo Grupo de Cooperação para Avaliação e pela Organizaçáo Internacional para Cooperaçáo em Avaliaçáo. 
aconteceu. (b) contrafactual: [...] o conhecimento sobre os impactos produzidos por uma intervençấo requer uma tentativa de aferir o que teria acontecido na ausência da intervenção e a comparação com o que tem ocorrido com a implementação da intervenção. (Leeuw; Vaessen, 2009, p. 9) ${ }^{10}$

Nesse sentido, haveria uma diferenciação metodológica relacionada ao uso de "avaliaçáo de resultados" (entendida como medida do que aconteceu) e "avaliaçáo de impactos": a atribuiçáo de causalidade e a definiçấo de um contrafactual. Principalmente o último elemento (contrafactual) parece ser a chave, na opiniāo da autora, para a diferenciação entre resultados e impactos, pois é possível avaliar "resultados" (o que aconteceu após a intervenção) sem estabelecer um grupo de comparação, mas este último parece essencial para se falar em impactos. Esse será o entendimento de impacto assumido neste trabalho.

A avaliação dos efeitos que são dependentes de uma intervenção é, por sua natureza, extremamente complexa, visto que questóes relativas à inferência causal estáo implícitas nesse tipo de avaliação (Sulbrandt, 1993).

Ora, nas ciências biológicas e exatas, isolar o efeito de uma variável pode ser mais simples do que nas ciências sociais. Como isolar, por exemplo, o efeito de um curso na prática de um profissional, sem a possibilidade de controlar os conhecimentos que ele tinha anteriormente?

Quando se trata de avaliar efeitos de um programa sobre o ser humano, cujas açóes e reaçóes envolvem uma complexidade de fatores, é possível eliminar outras explicações que possam justificar parcialmente o resultado da avaliação? É possível desenvolver indicadores ou instrumentos de medida de resultados que isolem os aspectos que podem ter interferido no processo e reflitam diferenças no objeto que sofreu a intervenção, antes e depois de ela ter ocorrido?

10 "Although there is debate within the profession about the precise definition of impact evaluation, NONIE's use of the term proceeds from its adoption of the Development Assistance Committee (DAC) of the Organization for Economic Co-operation and Development (OECD) definition of impact, as 'the positive and negative, primary and secondary long-term effects produced by a development intervention, directly or indirectly, intended or unintended'. Adopting the DAC definition of impact leads to a focus on two underlying premises for impact evaluations: (a) attribution: the words 'effects produced by' [...] imply an approach to impact evaluation that is about attributing impacts to interventions, rather than just assessing what happened. (b) counterfactual: [...] knowledge about the impacts produced by an intervention requires an attempt to gauge what would have occurred in the absence of the intervention and a comparison with what has occurred with the intervention implemented." (Leeuw; Vaessen, 2009, p. 9) 
Soma-se a essas questóes uma outra, anterior à própria medida de resultados: há informaçôes disponíveis sobre a implementaçâo do programa, para que se possa controlar outros fatores que possam intervir nos resultados alcançados?

Além disso, observa-se que objetivos e metas de avaliação, muitas vezes, náo sáo bem definidos, ou mudam constantemente, dificultando a aferição dos resultados esperados e inesperados por falta de parâmetros bem definidos para balizar essa avaliação. Assim, as alteraçóes constantes na agenda política que, frequentemente, imprimem modificaçôes no desenho e na implementação dos programas, dificultam a realização de avaliaçōes de impacto, que requerem metodologias mais complexas e com mais controle sobre as variáveis, a fim de que os resultados obtidos sejam confiáveis.

$\mathrm{Na}$ visāo de Sulbrandt (1993), os aspectos mais importantes dos programas sociais que dificultam aferiçóes de impacto são:

a) Os problemas estruturais que se pretende enfrentar mediante as políticas e programas que sáo debilmente estruturados e náo podem ser definidos de maneira rigorosa.

b) As políticas e programas, desenhados e aprovados pelo governo, não perseguem um objetivo único, mas sim objetivos múltiplos, às vezes inconsistentes, e suas metas, da qual emanam náo somente problemas técnicos, mas também necessidades táticas para assegurar sua aprovação, são definidas de maneira ambígua.

c) As metas tendem a ser redefinidas no transcurso da implementação. Uma das razóes que explicam estas modificaçóes e mudanças de metas é o processo de aprendizagem social que uma organização experimenta ao desenvolver um programa.

d) O caráter fraco das tecnologias utilizadas na quase totalidade dos programas sociais significa que as supostas relaçóes causais, que vinculam os insumos e as atividades com os produtos, resultados e impactos, náo respondem a um conhecimento certo e válido, mas sim que, no melhor dos casos, constituem somente hipóteses a verificar. (p. 325-326)

Segundo Sulbrandt (1993) e Rossi e Freeman (1989) esses dificultadores para a realização de uma avaliação de impacto ocorrem com bastante frequência, principalmente se o programa não prevê esse tipo de avaliaçáo e, portanto, náo há a preocupação direta com fatores essenciais para sua realizaçáo. 
Dentre os autores e instituiçóes que tratam da metodologia de avaliação pertinente à análise de impactos consultados para a elaboração deste artigo, observa-se que algumas características comuns são apresentadas:

- Definição das questôes essenciais da avaliação relativas aos impactos como resultados esperados e levantamento de explicaçóes alternativas para os resultados obtidos (relativas à seleção, atrito, efeitos externos, maturação, instrumentação) ${ }^{11}$.

- Estabelecimento de um contrafactual (o que teria acontecido com a população alvo na ausência do programa).

- Seleçáo aleatória dos participantes do estudo, tanto para o grupo de "tratamento" (o que receberá a intervenção) quanto para o grupo de "controle" (que propiciará a observaçáo do contrafactual), garantindo, ao mesmo tempo, equivalência em características que podem afetar o estudo (p. ex.: mesma classe social, faixa etária, nível de escolaridade, etc.)

- Comparação dos participantes do programa antes e depois de terem recebido a intervenção, a fim de verificar se houve ganhos de acordo com os resultados esperados.

- Comparação entre os resultados do grupo de controle e do grupo dos participantes do programa, para verificar se os resultados dos participantes excedem os resultados dos que não receberam a intervenção.

- Contextualização da avaliação (Leeuw; Vaessen, 2009; Cohen; Franco, 2008; OECD, 2008; Shadish; Cook; Campbell, 2002; Weiss, 1998).

A bibliografia de referência também destaca que os desenhos de pesquisa mais adequados à aferiçáo de impactos seriam os experimentais e quase-experimentais, principalmente os que utilizam grupo de controle e o modelo pré-teste/pós-teste (Shadish; Cook; Campbell, 2002).

Contudo, na impossibilidade de utilização desses desenhos de pesquisa, Donald Campbell alerta que a habilidade do pesquisador para excluir qualquer explicaçáo

${ }^{11}$ É importante definir o que pode ter influenciado nos resultados do programa, além da intervenção propriamente dita para, por meio do desenho da avaliação, tentar superar tais fatores intervenientes nos resultados. Muitos desses fatores podem ser desvelados pelo estudo das ameaças à validade (threats to validity), que muitos metodologistas que se dedicam ao desenho de pesquisa e avaliação sumarizam. Apresentar e discutir essas questóes foge aos objetivos deste artigo. Entretanto, o leitor interessado em aprofundar seus conhecimentos nessa temática pode consultar Shadish, Cook e Campbell (2002). 
alternativa para os resultados obtidos pela intervenção é essencial para a aferição de efeitos e impactos, mais do que o desenho de pesquisa (Weiss, 1998, p. 183).

Nesse sentido, a ideia comum de que efeitos e impactos só podem ser mensurados em desenhos experimentais e quase-experimentais, nos quais o pesquisador tem mais controle sobre as variáveis, e que dificilmente sáo aplicados em ciências sociais, pode ser questionada, e o debate desloca-se para o desafio que o estudioso tem que enfrentar nessa área: buscar aferir impactos, usando modelos não-experimentais de pesquisa.

Observa-se, entáo, a necessidade de desenvolver modelos alternativos de análise de impactos de uma intervenção que considerem as informaçóes já existentes, que sejam factíveis e possam iluminar o entendimento sobre os resultados das açôes realizadas, contribuindo com a gestáo pública de serviços educacionais.

Isso implica a necessidade de retomar a discussão, em educação, sobre as tecnologias de análise disponíveis para que se isolem explicaçóes alternativas sobre os resultados dos programas implementados como, por exemplos, açóes de formação docente. Mas, para isso, é preciso também debater, com os formuladores de políticas, quais os cuidados necessários, já na implementaçáo do programa, para que informaçôes essenciais às avaliaçôes de impacto possam ser produzidas ou coletadas.

Além disso, ante as dificuldades de mensurar impactos desse tipo de programa, cabe a discussão sobre como potencializar o uso das informaçóes obtidas pelos sistemas de avaliação já existentes, visando a analisar e compreender a realidade educacional em sua complexidade e possibilitando a proposição de políticas baseadas em dados confiáveis.

Discutir as experiências de avaliaçáo de impactos que têm sido geradas no âmbito das universidades e das instituiçóes de pesquisa especializadas em avaliaçáo pode servir para iluminar os meandros metodológicos da medida de impactos de programas de formação e a discussão sobre possibilidades e limites de estudar impactos sem utilizar métodos experimentais ou quase-experimentais. Tais preocupaçóes motivam o compartilhar dos percalços gerados pela pesquisa até o presente momento, pois a busca de soluçóes para essa questáo deveria, antes de tudo, ser coletiva.

\section{(DES)CAMINHOS DA PESQUISA: HÁ LUZ NO FIM DO TÚNEL?}

No que se refere à formação docente, um estudo bibliográfico inicial mostrou que apesar da década de 1990 ser marcada pela proliferação de estudos sobre a formação dos professores e seu caráter de desenvolvimento profissional, observa-se que 
o investimento em programas de formação continuada náo parece estar contribuindo, como esperado pelos elaboradores de políticas e programas educacionais, para a melhoria da qualidade de ensino (Navarro, 2003).

É importante destacar que a existência da relação direta entre formaçáo docente e desempenho dos alunos gera muitas controvérsias entre os pesquisadores e estudiosos, e nem sempre é aceita pela comunidade científica. Enquanto alguns autores acreditam que a relação entre a formaçáo dos professores e o desempenho dos alunos é frágil (Torres, 1998), outros defendem que esses elementos estão intimamente relacionados (Brunner, 2003; Castro, s/d).

A análise de Marta Sisson de Castro (s/d), por exemplo, aponta a relação direta entre a formação dos professores, em nível superior, e os resultados dos alunos no PISA:

Os resultados do PISA também constataram: "o conjunto de fatores escolares explica $31 \%$ da variância na leitura" (PISA, 2002). Ao identificar os fatores escolares que influenciam positivamente o rendimento acadêmico dos alunos, enfatizam que professores qualificados sáo os recursos escolares mais valiosos. Foi constatada uma associação entre a percentagem de professores que possuíam curso superior em sua área de atuação e resultado acadêmico dos alunos; por exemplo, uma elevação de $25 \%$ no percentual de professores com curso superior em sua área de atuação está associado com um aumento de nove pontos no teste de leitura, em média, nos países da Organization for Economic Co-operation and Development (OECD), indicando que a preparaçáo dos professores afeta diretamente o rendimento dos alunos. [grifos meus]

Tal relação precisa ser tematizada por estudos que se dediquem à compreensão da política educacional, pois enquanto não são traçadas conclusóes mais precisas ela não pode ser descartada como um dos elementos explicativos do sucesso ou fracasso de determinado programa, nem, tampouco, ser tomada como verdade absoluta. No caso específico da análise sobre a influência do Programa Letra e Vida nos desempenhos de alunos e professores, a intenção da pesquisadora é buscar informaçóes que possam contribuir para o avanço da discussáo dessa polêmica.

Heraldo Vianna ensina que é por meio da avaliação de um programa, aliado à pesquisa, que será possível desvendar a "rede de fatores confluentes e que se interpenetram, gerando uma rede de causas, fatos e efeitos" que interferem na realidade educacional e, portanto, na qualidade em educaçáo (Vianna, 2005, p. 23).

Feitas tais ressalvas, e com base nas análises iniciais da autora, que tomou os resultados obtidos pelos alunos no Sistema de Avaliação de Rendimento Escolar de São Paulo (Saresp) em 2007 como indício do desempenho discente, náo é possível 
afirmar que tais resultados se alteraram em razáo do Programa Letra e Vida oferecido aos professores de $1^{\text {a }}$ série, desde que foi implantado.

Vale destacar que a relação entre a prova do Saresp e os pressupostos teóricometodológicos divulgados no curso existe e é colocada com clareza em documento retirado do site da Secretaria da Educação, à época da inscrição das escolas no Saresp, no qual são explicitadas as matrizes de referência que embasam a elaboraçáo da prova de $1^{\mathrm{a}}$ e $2^{\mathrm{a}}$ séries:

A avaliação das primeiras séries do Ensino Fundamental está vinculada à existência de professores nas redes municipal e particular que participaram do Programa de Formaçáo de Alfabetizadores (PROFA) ${ }^{12}$, ministrado pelo Ministério da Educaçáa, ou do Projeto Letra e Vida, em desenvolvimento pela Secretaria da Educaçáo do Estado de São Paulo. Essa decisão se justifica em razão da especificidade da avaliação das $1^{\text {a }}$ e $2^{\text {a }}$ séries na rede da SEE que, vinculada aos pressupostos desse Projeto, requer procedimentos específicos para a aplicação e correção de provas. (São Paulo, s/d)

Isso porque não é possível identificar, nos resultados do Saresp, uma continuidade metodológica e temporal que permita fazer afirmaçóes fidedignas a esse respeito.

Implantado a partir de 1996, com periodicidade irregular, o Saresp já realizou dez avaliaçóes nas escolas da rede estadual de São Paulo (Quadro 1), inclusive, em alguns anos, houve a participação de algumas redes municipais e escolas particulares.

\section{Quadro 1 - Edições do Saresp e séries avaliadas, por edição}

\begin{tabular}{|c|c|c|c|c|c|c|c|c|c|c|c|}
\hline \multirow{2}{*}{ Ano } & \multicolumn{8}{|c|}{ Ensino fundamental } & \multicolumn{3}{|c|}{ Ensino médio } \\
\hline & $1^{\mathrm{a}}$ & $2^{\mathrm{a}}$ & $3^{a}$ & $4^{a}$ & $5^{a}$ & $6^{a}$ & $7^{\mathrm{a}}$ & $8^{a}$ & $1^{\mathrm{a}}$ & $2^{a}$ & $3^{\mathrm{a}}$ \\
\hline 1996 & & & 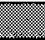 & & & & 28 & & & & \\
\hline 1997 & & & & & & & & 2 & & & \\
\hline 1998 & & & & & 2 & & & & 20 & & \\
\hline 2000 & & & & & 2. & & 2 & & & & 878 \\
\hline 2001 & & & & & & & & 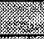 & & & \\
\hline 2002 & & & & & & & & 2 & & & \\
\hline 2003 & & & & & & & & & & & \\
\hline 2004 & & & & Y & & & & . & & & \\
\hline 2005 & & & & 2. & 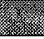 & & 2 & (2.) & & & \\
\hline 2007 & & & & 10 & & & & $\sqrt{3}$ & & & 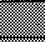 \\
\hline 2008 & & & & 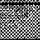 & & 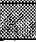 & & 17 & & & 28 \\
\hline
\end{tabular}

${ }^{12}$ O Programa Letra e Vida é o mesmo Programa de Formação de Alfabetizadores (PROFA) que havia sido implantado em 2001 pelo Ministério da Educação. Contudo, na experiência do PROFA a adesão dos municípios era voluntária. Os pressupostos teóricos e metodológicos, no entanto, são os mesmos, e observam-se poucas diferenças no material utilizado nos dois cursos. 
Para o interesse específico da pesquisadora, observa-se que os alunos da $1^{a}$ série do ensino fundamental foram avaliados em 2003, 2004, 2005 e 2007. O Programa Letra e Vida foi implantado em 2003, o que permitiria supor que os resultados de 2004, 2005 e 2007 pudessem sofrer alteraçóes em comparação aos de 2003 devido à açâo de formaçáo docente.

Contudo, não é possível realizar uma análise longitudinal dos resultados da $1^{a}$ série. Em 2003, por exemplo, ela foi qualitativa, não sendo atribuídas porcentagens médias para os acertos dos alunos, como mostra o trecho do Relatório do Saresp 2003:

Cabe ressaltar que as provas das $1^{\text {a }}$ e $2^{\text {a }}$ séries do Ensino Fundamental foram corrigidas de forma qualitativa, sendo criadas categorias de desempenho; portanto, nessas séries não serão discutidas as porcentagens médias de acertos em cada habilidade, mas a porcentagem de alunos em cada categoria, por tópico de análise. As categorias de classificação das respostas dessas duas séries foram determinadas por especialistas da SEE/SP. (São Paulo, 2003)

Em 2003, os alunos foram distribuídos em níveis, segundo uma escala de desempenho como mostra o quadro 2 .

Observa-se que a análise dos resultados manteve-se qualitativa, mas, diferentemente do ano anterior, associou-se um total de pontos a cada nível de desempenho.

Houve, assim, uma alteraçáo no tratamento dos resultados que dificultou o estudo mais direto dos desempenhos das duas avaliaçóes. Tais análises poderiam ser feitas sobre os resultados qualitativos, presentes nas duas amostras, mas as mudanças ocorridas nos descritores qualitativos poderiam levar a conclusóes errôneas a respeito dos resultados e de sua relaçáo com o programa de formação avaliado. Além disso, como não ocorreu um controle específico da questão da formação do professor, não foi possível distinguir, entre os avaliados, os que eram e os que não eram alunos de professores que haviam participado do programa.

Finalmente, a pesquisadora também perdeu a possibilidade de análise e utilização dos resultados da $1^{a}$ série, obtidos em 2005 e 2007, visto que houve alteraçáo significativa no esquema de pontuação da avaliação, e também mudanças na disposição das categorias qualitativas. 
Quadro 2 - Níveis da escala de desempenho do Saresp 2003 para a $1^{\text {a }}$ série do ensino fundamental

\begin{tabular}{|l|l|}
\hline Níveis da escala de desempenho em leitura e escrita & Ensino fundamental - ciclo I - 1a série \\
\hline NÍVEL DE DESEMPENHO: INSUFICIENTE (de 0 a 9 pontos) & $\begin{array}{l}\text { Neste nível, os alunos ainda não } \\
\text { escrevem com correspondência sonora } \\
\text { alfabética. }\end{array}$ \\
\hline NÍVEL DE DESEMPENHO: REGULAR (de 10 a 12 pontos) & $\begin{array}{l}\text { Neste nível, os alunos escrevem com } \\
\text { correspondência sonora alfabética. }\end{array}$ \\
\hline NÍVEL DE DESEMPENHO: BOM (de 13 a 18 pontos) & $\begin{array}{l}\text { Neste nível, os alunos escrevem com } \\
\text { correspondência sonora alfabética e } \\
\text { leem com autonomia, localizando } \\
\text { parcialmente informações no texto. }\end{array}$ \\
\hline NÍVEL DE DESEMPENHO: MUITO BOM (de 19 a 20 pontos) & $\begin{array}{l}\text { Neste nível, os alunos escrevem } \\
\text { alfabeticamente com ortografia regular } \\
\text { eleem com autonomia, localizando } \\
\text { integralmente informações no texto e } \\
\text { sendo capazes de inferir uma } \\
\text { informação a partir da leitura. }\end{array}$ \\
\hline NÍVEL DE DESEMPENHO: OTIMO (de 21 a 24 pontos) & $\begin{array}{l}\text { Neste nível, os alunos escrevem } \\
\text { alfabeticamente com ortografia regular } \\
\text { e leem com autonomia, sendo capazes } \\
\text { de inferir uma informação a partir da } \\
\text { leitura. Produzem texto com algumas } \\
\text { características de linguagem escrita e do } \\
\text { gênero proposto (carta). }\end{array}$ \\
\hline NÍVEL DE DESEMPENHO: EXCELENTE (25 pontos) & $\begin{array}{l}\text { Neste nivel, os alunos escrevem } \\
\text { alfabeticamente com ortografia regular } \\
\text { eleem com autonomia, sendo capazes } \\
\text { de inferir uma informação a partir da } \\
\text { leitura. Produzem texto com } \\
\text { características de linguagem escrita e do } \\
\text { gênero proposto (carta). }\end{array}$ \\
\hline
\end{tabular}

Fonte: São Paulo, 2004.

Inicialmente, pensou-se que ao usar os dados do Saresp 2005 e 2007 propiciaria um estudo com pré-teste e pós-teste, a partir do qual se buscaria observar tendências de desempenho dos alunos e escolas cujos professores participaram do programa analisado. Contudo, enquanto o Saresp 2005 foi analisado de acordo com um escore máximo de 44 pontos, distribuídos em 8 níveis de escala de desempenho, no Saresp 2007 foram adotados 6 níveis de escala de desempenho, com uma pontuaçáo máxima de 49 pontos, como mostram os quadros 3 e 4 . 
Quadro 3 - Níveis da escala de desempenho em leitura e escrita

na $1^{\text {a }}$ série do ensino fundamental. Saresp 2005

\begin{tabular}{|c|c|l|}
\hline Nível & Pontuação & \multicolumn{1}{c|}{ Descrição dos Níveis } \\
\hline $\begin{array}{c}\text { Abaixo } \\
\text { do nível 1 }\end{array}$ & $0-4$ & $\begin{array}{l}\text { Alunos que não demonstram domínio das habilidades avaliadas } \\
\text { pelos itens da prova. }\end{array}$ \\
\hline 1 & $5-9$ & \begin{tabular}{l} 
Escrevem com correspondência sonora ainda não alfabética. \\
\hline 2
\end{tabular} \\
\hline 3 & $13-12$ & Escrevem com correspondência sonora alfabética. \\
\hline 4 & $19-25$ & $\begin{array}{l}\text { Escrevem com correspondência sonora alfabética e leem com } \\
\text { autonomia (texto informativo). }\end{array}$ \\
\hline 5 & $26-38$ & $\begin{array}{l}\text { Escrevem com ortografia regular. } \\
\text { Produzem texto com algumas características de linguagem } \\
\text { escrita e do gênero proposto (conto). }\end{array}$ \\
\hline 6 & $39-40$ & $\begin{array}{l}\text { Produzem texto com características de linguagem escrita e do } \\
\text { gênero proposto (conto). }\end{array}$ \\
\hline 7 & $41-44$ & $\begin{array}{l}\text { Produzem texto com características de linguagem escrita e do } \\
\text { gênero proposto (texto informativo), a partir de situação de } \\
\text { leitura autônoma e de texto de outro gênero. }\end{array}$ \\
\hline
\end{tabular}

Fonte: FDE, 2008.

Quadro 4 - Níveis da escala de desempenho em leitura e escrita na $1^{\text {a }}$ série do ensino fundamental. Saresp 2007

\begin{tabular}{|c|c|l|}
\hline Nível & Pontuação & \multicolumn{1}{c|}{ Descrição dos Níveis } \\
\hline 1 & $0-3$ & Os alunos escrevem sem correspondência sonora. \\
\hline 2 & $4-8$ & $\begin{array}{l}\text { Os alunos escrevem com correspondência sonora ainda não } \\
\text { alfabética. }\end{array}$ \\
\hline 3 & $9-16$ & Os alunos escrevem com correspondência sonora alfabética. \\
\hline 4 & $17-25$ & $\begin{array}{l}\text { Os alunos escrevem com correspondência sonora alfabética e } \\
\text { produzem texto com algumas características da linguagem } \\
\text { escrita e do gênero proposto (carta). }\end{array}$ \\
\hline 5 & $26-37$ & $\begin{array}{l}\text { Os alunos escrevem com ortografia regular; produzem texto com } \\
\text { características da linguagem escrita e do gênero proposto (carta); } \\
\text { e, localizam, na leitura, informações explícitas contidas no texto } \\
\text { informativo. }\end{array}$ \\
\hline 6 & $38-49$ & $\begin{array}{l}\text { Os alunos escrevem com ortografia regular; produzem texto com } \\
\text { características da linguagem escrita e do gênero proposto (carta); } \\
\text { localizam informações explícitas; e fazem inferência de } \\
\text { informações a partir de um texto lido (texto informativo). }\end{array}$ \\
\hline
\end{tabular}

Fonte: FDE, 2008. 
Observa-se que a própria distribuição dos alunos nos níveis, feita pela Secretaria da Educação e seus assessores, parece deficitária, pois os níveis são distintos e definidos com base no número de pontos variável. Independentemente da precisão desses níveis, observa-se que a diferenciação entre os instrumentos e as formas de análise trazem, em seu bojo, questóes de instrumentação que, como explicado por Shadish, Cook e Campbell, consistem em uma ameaça à validade dos resultados da pesquisa caso o estudioso não consiga encontrar outras formas de análise, que náo uma comparação direta entre os resultados das diversas avaliaçôes.

A fim de tentar sobrepujar esses desafios impostos pela instrumentação, a pesquisadora optou por fazer uma análise exploratória, convertendo os resultados dos alunos em proporçóes. Em um exercício de reflexáo, visando a encontrar pontos em comum entre os grupos que foram avaliados em 2005 e 2007, tentou-se considerar os alunos com pontuaçáo igual ou maior que $75 \%$ nas duas provas e, para complemento do estudo, aqueles que atingiram menos de $25 \%$ da pontuação possível.

No caso de 2005, esses alunos eram aqueles que tiveram escores menores que 11 pontos e maiores que 33. Já no caso dos alunos avaliados em 2007 , foram considerados os que obtiveram pontos acima de 36,75 e abaixo de 12,25. Partindo dessa análise inicial, não foi possível observar alteraçóes nos desempenhos de alunos cujos professores participaram do curso de formação em alfabetizaçẫo, que é objeto de estudo, e novas possibilidades de análise ainda estáo sendo estudadas. Pode-se afirmar, contudo, que os resultados da análise exploratória não permitiram chegar a conclusôes que evidenciassem impactos do curso sobre o desempenho discente, ao contrário do que se propagou à época.

Isso não significa, contudo, que o Programa Letra e Vida não alcançou resultados positivos, visto que ele pode ter atingido seus objetivos com relação à formação de professores. Entretanto, do ponto de vista quantitativo, a formação não pareceu repercutir em diferenças significativas no aprendizado dos alunos. Tal descoberta reforçou a necessidade de investigar a prática docente dos que fizeram o curso, a fim de analisar em que medida ela seria influenciada pelos pressupostos aprendidos durante a atividade de formação continuada.

Outro fator que influenciou o delineamento da análise proposta foi a dificuldade de obtenção de informações sobre o nível socioeconômico da escola, uma vez que esse tipo de informaçāo nem sempre é incorporado aos questionários que acompanham as avaliaçóes sistêmicas. Ora, procurar comparar resultados entre amostras equivalentes é um princípio necessário para que o pesquisador evite que os resultados sejam inválidos por questóes de seleçáo das amostras. Assim, para poder afirmar que os resultados 
não estariam sofrendo mudanças, em razão de questóes de nível socioeconômico, mas sim sendo influenciados pela melhoria no desempenho do professor, por via da formaçâo continuada, tornou-se um desafio à pesquisadora a atribuição de uma medida de característica socioeconômica a cada escola ou aluno avaliado.

Nesse sentido, apresentou-se um dificultador: os alunos do ciclo 1 do ensino fundamental não estáo aptos a responder questóes de nível socioeconômico, o que justifica que os organizadores do Saresp só comecem a colher esses dados a partir da $4^{a}$ série.

Para tentar ultrapassar essa limitação no estabelecimento do nível socioeconômico da escola, optou-se, então, por obter dados parciais sobre a populaçáo atendida pelas escolas e, então, generalizá-los para toda a instituição. Como alternativa, utilizou-se os dados fornecidos pela Fundação para o Desenvolvimento da Educaçáo (FDE), que se baseou em uma adaptação do Critério Brasil ${ }^{13}$ para, com base nas respostas dos alunos de $4^{\text {a }}$ série, traçar o perfil socioeconômico da escola. O pressuposto assumido pela pesquisadora foi que a populaçáo atendida no entorno escolar é a mesma, estando os alunos no $1^{\circ}$ ou no $4^{\circ}$ ano do ensino fundamental.

Além disso, desde o início do projeto, a pesquisadora intentava verificar se haveria diferenças substanciais entre o desempenho de alunos de professores que cursaram o Programa Letra e Vida e o desempenho de alunos cujos professores náo participaram do curso que, como visto anteriormente, é condiçáo essencial a uma avaliaçáo de impacto.

Para estabelecer essa relação, seriam utilizadas as respostas dos professores ao questionário que acompanhou o Saresp de 2007 em que foram incluídas, a pedido da equipe do "Letra e Vida", questóes que permitissem identificar os docentes que participaram do programa. A ideia inicial, segundo a supervisora do programa, professora Telma Weisz ${ }^{14}$, era identificar os professores formados pelo "Letra e Vida" e cruzar essa informação com os resultados obtidos por seus alunos.

Contudo, durante a aplicação do Saresp, houve uma troca de professores aplicadores entre escolas, com exceção dos professores das duas séries iniciais do ensino fundamental. Nesse caso, os professores de $1^{\text {a }}$ e $2^{\text {a }}$ séries que aplicaram a avaliação foram os professores da própria escola, trocando, porém, as turmas.

${ }^{13}$ O Critério Brasil incorpora a escolaridade da máe e a posse de bens de conforto, mas não questóes específicas sobre renda.

${ }^{14}$ Informação obtida em entrevista concedida à pesquisadora em 2007. 
Isso fez com que os questionários dos professores de $1^{\mathrm{a}}$ e $2^{\mathrm{a}}$ séries não fossem respondidos pelos responsáveis de cada turma, perdendo-se a possibilidade de cruzar os dados obtidos pelos respondentes que fizeram o "Letra e Vida" com os percentuais de rendimento dos alunos, que seria uma fonte importante de informaçáo para a análise do impacto do programa. Novamente, para tentar superar esse problema, a pesquisadora optou por trabalhar com a escola como um todo enquanto unidade de pesquisa, e não mais com os professores individualmente. $\mathrm{Na}$ atual fase da pesquisa, busca-se encontrar informaçóes sobre a quantidade de professores que tinham participado do programa em 2007 e sua composiçáo em cada escola, em termos de proporção. Procurar-se-á, nesse sentido, estabelecer comparaçóes entre escolas com grande porcentagem de professores que participaram da formaçáo, e escolas com poucos professores que fizeram o "Letra e Vida", a fim de observar se há diferenças entre os resultados obtidos pelas instituiçóes que pertencem à mesma faixa socioeconômica.

Finalmente, cabe destacar que a proposta inicial de análise de possíveis impactos do Programa Letra e Vida contemplava o acompanhamento de um grupo de professores que foram cursistas do programa, comparando os resultados dos seus alunos com os de alunos de professores que não se submeteram a ele. Tal abordagem, contudo, foi dificultada porque ocorreram inúmeras remoçóes de docentes durante o ano, o que náo garante que, ao chegar à escola, a pesquisadora tenha acesso ao mesmo grupo que lá estava em 2007, ano em que se baseiam as informaçóes obtidas por ela por meio da FDE.

As dificuldades encontradas no decorrer da pesquisa permitem, desde já, chegar a duas conclusóes principais. Primeiramente, percebe-se que a própria natureza do sistema educacional de Sáo Paulo dificulta a análise de resultados baseada em uma metodologia que exige o controle de variáveis e, portanto, a manutençáo de algumas estruturas propostas inicialmente.

Programas que mudam constantemente, informaçốes que não são "controladas" pelos aplicadores do Saresp (e que poderiam ser úteis à gestáo do sistema), desafios técnicos e metodológicos para manutençáo da unicidade nas propostas e equivalência de resultados constituem parte dos aspectos que devem ser considerados, se o objetivo é o desenvolvimento de análises mais aprofundadas e sustentáveis, com validade interna e externa.

Em segundo lugar, chama a atenção a postura da Secretaria da Educaçáo que poderia imprimir mudanças no sentido de propiciar condiçóes mais favoráveis para o desenvolvimento das pesquisas em educação e para o aprimoramento da reflexáo teórica sobre as análises de resultados referentes ao sistema educacional. 
Paralelamente, observa-se que as mesmas dificuldades enfrentadas pela pesquisadora devem se impor, de alguma maneira, ao pessoal técnico da Secretaria, dificultando-lhes o trabalho de análise dos resultados obtidos.

De qualquer forma, um maior cuidado na organização das avaliaçōes e no tratamento de dados sobre professores poderia ser decisivo para ajudar no desenvolvimento de uma proposta de avaliaçáo de impacto.

Contudo, são essas mesmas dificuldades que fazem com que seja necessária a realizaçáo de estudos como o que está sendo proposto neste projeto, a fim de contribuir para o acúmulo de conhecimentos na área de avaliação de impacto de programas sociais que deve ser focalizada nos próximos anos, tendo em vista as características que a gestão de programas sociais e educacionais vêm assumindo ultimamente.

\section{REFERÊNCIAS BIBLIOGRÁFICAS}

BAKER, J. Evaluating the impact of development projects on poverty: a handbook for practitioners. Washington: World Bank, 2000. (Direction in development).

BAUER, A. Usos dos resultados do Saresp: o papel da avaliação nas políticas de formação docente. 2006. Dissertação (Mestrado em Educação) Faculdade de Educação, USP, São Paulo.

BICKMAN, L. Impact assessment. In: MADISON, S. Encyclopedia of evaluation. California: SAGE, 2005, p. 194.

BRUNNER, J. J. Límites de la lectura periodística de resultados educacionales. In: UNESCO. Evaluar las evaluaciones: una mirada política acerca de las evaluaciones de la calidad educativa. Buenos Aires: UNESCO/IIPE, 2003, p. 67-84.

CASTRO, M. L. S. Avaliação do rendimento educacional e a formação de professores. Porto Alegre, [2008]. Disponível em: <http://www. sbec.org.br/evt2008/trab28.pdf>. Acesso em: 28 nov. 2008.

COHEN, E.; FRANCO, R. Avaliação de projetos sociais. Petrópolis: Vozes, 2008.

INDEPENDENT EVALUATORS' WEBRING. Definitions of evaluation types, approaches and fields. Disponivel em: <http://www.evaluatorswebring.net/Independent_evaluators_ webring_definitions_May06.pdf $>$. Acesso em: 20 nov. 2008. Version as at May 2006.

LAVILLE, C.; DIONNE, J. A Construção do saber: manual de metodologia de pesquisa em ciências humanas. Porto Alegre: Artmed; Belo Horizonte: UFMG, 1999.

LEEUW, F.; VAESSEN, J. Impact evaluations and development: NONIE'S guidance on impact evaluation. Washington: World Bank, 2009.

MADISON, S. Encyclopedia of evaluation. California: SAGE, 2005.

MOHR, L. Impact analysis for program evaluation. California: SAGE, 1992.

NAVARRO, J. C. La Evaluación y las actitudes de los docentes frente a ella: dificultades y alternativas de política. In: UNESCO. Evaluar las evaluaciones: una mirada política acerca de las evaluaciones de la calidad educativa. Buenos Aires: Unesco/IIPE, 2003. p. 147-164.

NATIONAL SCIENCE FOUNDATION. An Overview of quantitative and qualitative data collection methods. Disponível em: <http://www.nsf. gov>. Acesso em: 15 nov. 2007. 
OECD. Draft NONIE statement on impact evaluation. In: MEETING OF THE DAC NETWORK ON DEVELOPMENT EVALUATION, 7., 20-21 Feb. 2008. [S.I.]. Disponivel em: <http://www.oecd. $\mathrm{org} /$ dataoecd/19/29/40104352.pdf>. Acesso em: 17 nov. 2008.

Outline of principles of impact evaluation. Disponível em: <http://www.oecd. org/dataoecd/46/16/37671602.pdf.> Acesso em: 19 mar. 2010.

ROSSI, P.; FREEMAN, H. Monitoreo del programa para su evaluación. Evaluación: un enfoque sistemático para programas sociales. México: Trillas, 1989.

SÃO PAULO (Estado). Secretaria da Educação. Condições de adesão da rede municipal $e$ particular. São Paulo, [S.d.]. Disponível em: <http://saresp.edunet.sp.gov.br/2004/ subpages/condi_ad_mu.htm>. Acesso em: 21 abr. 2009.

- Conhecendo os resultados do Saresp 2003. São Paulo: FDE, 2005. .Niveis da escala de desempenho em leitura e escrita: ensino fundamental - ciclo I- 1a $^{\text {a }}$ e $2^{\text {a }}$ séries. 2004. Disponível em: <http://www. educacao.sp.gov.br/noticias_2005/01_02_ EF.pdf >. Acesso em: 21 abr. 2009.

- Política educacional da Secretaria da Educaçâo do Estado de São Paulo, 2003.
Disponivel em: <http://www.crmariocovas. sp.gov.br/pdf/ors/PoliticaSEE.pdf.> Acesso em: 20 abr. 2009.

. Sumário executivo do Saresp 2005

e 2007. São Paulo: FDE, 2008. Disponível em: <http://www.educacao.sp.gov.br/saresp >. Acesso em: 20 abr. 2009.

SCRIVEN, M. Evaluation thesaurus. California: SAGE, 1991.

SHADISH, W.; COOK, T.; CAMPBELL, D. Experimental and quasi-experimental designs for generalized causal inference. Boston: Brooks/ Cole, 2002.

STUFFLEBEAM, D.; WEBSTER, W. An analysis of alternative approaches to evaluation. Educational Evaluation and Policy Analysis, California, v. 2, n. 3, May/Jun. 1980.

SULBRANDT, J. La Evaluación de los programas sociales: una perspectiva crítica de los modelos usuales. Caracas: CLAD, 1993, p. 309-350.

TORRES, R.M. Tendências da formação docente nos anos 90. In: WARDE, M. (Org.). Novas políticas educacionais: críticas e perspectivas. São Paulo: PUC-SP, 1998. p. 173-191.

VIANNA, H. M. Fundamentos de um programa de avaliação educacional. Brasília: Líber Livro, 2005. WEISS, C. Evaluation: methods for studying program and policies. $2^{\text {th }}$ ed. New Jersey: Prentice Hall, 1998. 